\title{
Six Minute Walk Test as a Criteria for Evaluation of Functional Status and Disability by One Time Single Measurement of Distance Walked in Six Minutes for Breathless Patients
}

\author{
Pradeep Kumar Vyas*, Suresh V Rang, Jayant R Shah, Rajiv S Mathur, Gaurav Ghatavat and Priyanka \\ Chaudhary \\ Department of Respiratory Medicine, Jaslok Hospital and Research Centre, India
}

Submission: November 30, 2016; Published: March 30, 2017

*Corresponding author: Dr. Pradeep Kumar Vyas, Department of Respiratory Medicine, Jaslok Hospital and Rsearch Centre, 15 Dr. G. Deshmukh Marg, Mumbai, Pin code: 91400026, India, Tel: 912266573212; 9920696710; Fax No: 912223520508: E-Mail: drvyaspradeep@gmail.com

\begin{abstract}
6 Minute Walk Test is increasingly used in clinical practice, as an objective measurement of functional status in patients with moderate to severe impairment. It is one of the simple tests of low complexity that measures the distance a patient can walk in 6 minutes. The 6MWT is useful to assess response to medical interventions, prognosis and as single measurement of functional status in cardio respiratory disability.

Objective: There are few studies done in India that prompted us to do this study with the objective to evaluate functional status and disability by one-time measurement of 6-minute walk distance in patients with complains of breathlessness.

Methods: 121 Patients with complains of breathlessness were registered for the study between June 2010 to July 2011. Test procedures, purpose of the study were explained to participants. The materials used, patient's preparation and layout was done using ATS-2002 guidelines. The participants were asked to walk at their self-selected pace, attempting to cover as much distance as possible in 6 minutes. The total distance walked in 6 minutes was recorded.
\end{abstract}

Result: 121 patients were evaluated. Mean age, height and weight was 56.75 years, $161.80 \mathrm{~cm}$ and $64.93 \mathrm{~kg}$ respectively. 101 patients completed the test, mean 6MWD was 390.08 meters (males 410.45, females 356.13m). 6MWD was significantly decreased in cardiopulmonary diseases.

Conclusion: In our study we demonstrated that 6MWT can be safely performed even in patients with advanced cardiopulmonary conditions. It is a useful marker for the severity, progression and prognosis.

Keywords: 6MWT; 6MWD; Incremental Scuttle Walk Test; Cycle-Ergomerty, Cardiac Stress Test; CPET; PFT

\section{Introduction}

Walk testing was first advocated by "Balke" in 1963 to assess physical fitness. K. H. Cooper used 12MWT in healthy air force personnel to demonstrate a strong correlation between maximal oxygen consumption and maximal exercise testing. McGavin used walk test to assess disability in COPD patients. 6MWT was introduced as functional exercise test by Lipkin in 1986 which correlated with those of 12MWT and cycle ergometry or treadmill. Although PFT continues to play a major role in management and research (FEV1and FVC is used to assess severity of breathlessness). The effectiveness and reliability of the 6MWT became the most widely accepted protocol to assess functional dusability. Walking is a measure of functional status of daily activities. 6MWT is practical, simple, requires the ability to walk. The distance a patient walks on a flat surface in 6 minutes is used as a one-time measurement of functional status, or improvement during rehabilitation. The test is selfpaced, reflects the exercise level needed for daily tasks [1], can be done by a technician. In 2002 ATS [1] outlined guidelines for $6 \mathrm{MWT}$ which reviewed the physiological response to exercise. Guidelines were used to limit controllable factors for variability (use of practice test, oxygen and medications prior to or during 
testing).Technician does not walk with the patient to avoid influencing the patient's pace. Measurement of SPO2 is optional, the test is usually terminated if the SP02 falls below 85\% [2], however it can be continued depending on experience of the physician. In patients on long term oxygen therapy the 6MWT can be performed with portable oxygen. The 6MWT should be performed by a technician certified in cardio-pulmonary resuscitation at the basic life support level although advanced cardiac life support certification is desirable. Test is terminated when there are signs of severe distress, confusion, dizziness, diaphoresis, severe dyspnoea, fatigue. The patients were allowed to stop if mild distress occurred, however they were asked to resume walking. The patients were observed for 10-15 minutes after the test, patients who started to walk but did not complete the test were included in the study.

\section{Indications}

a. Response to medical interventions in patients with moderate to severe cardio-pulmonary diseases.

b. One-time measurement of functional status as a criterion for pulmonary affection and disability.

c. Pre and post pulmonary surgery evaluation.

d. Cardio pulmonary predictors of morbidity and mortality.

\section{Materials and methods}

\section{Inclusion Criteria}

Stable patient's between13-85 years of age with complaints of breathlessness.

\section{Exclusion Criteria}

Myocardial Infarction in the preceding month, unstable angina, resting heart rate $>120 / \mathrm{min}$, systolic $\mathrm{BP}>180 \mathrm{~mm}$ $\mathrm{Hg}$, diastolic BP $>100 \mathrm{~mm} \mathrm{Hg}$, syncope, arthritis, skeletal or neuromuscular diseases. Stable angina is not an absolute contraindication (after taking anti angina drugs).

\section{Test Procedure}

The test was performed on a flat surface corridor of 15-meter length (recommendation is $15-30$ meters) marked with small cones at the starting and end points and at every $3 \mathrm{~m}$ distance, the time and laps were recorded on a worksheet. Patients were asked to wear comfortable clothes, take light meals, to sit for 10 minutes at the starting point for check on contraindication, informed written consent was taken and details of test procedure and risk associated were explained. Medical history with clinical examination was undertaken along with BMI, BP, Borg scores for dyspnoea and fatigue with resting heart, respiratory rate and SPO2 were recorded after 10 minute's rest, and after completion of the test. Spirometry was performed and data collected as per ATS guidelines. The patients were asked to walk while attempting to cover as much distance as possible in 6 minutes.

\section{Measurement}

The total distance walked in meters in 6 minutes with number of rest and stops during the test were also recorded.

\section{Statistical Analysis}

Statistical analysis was performed with statistical software SPSS (Statistical Package for Social Sciences). The distribution of continuous variables was used for normality. The data were presented as mean+SD, except where otherwise specified. Rates and proportions were analyzed by Fisher's exact test and $\mathrm{x} 2$ test of general association where appropriate. The data were checked for normality using Kolmogorov Smirnov Z-test for individual variables of all groups. Pearson product correlation was used to assess for relationships among appropriate variables, two sample student- $\mathrm{t}$ test with assumption of unequal variance measured during 6MWT alone (age, sex, height, weight, body mass index), distance ambulated, resting and exercise heart rate, blood pressure, respiratory rate, oxygen saturation were evaluated for their association with 6MWD by first univariate analysis with the spearman's correlation test and then adjusted to multivariate analysis using stepwise multiple linear regression. To determine entry and removal of candidate variables from the model P-values of 0.05 and 0.01 were used respectively. KaplanMeier method was used to compare patients by categories of 6MWD (<149- severe, 150-249 moderate, 250-349 mild, >350 normal). 6MWD measured in our study was compared with predicted 6MWD derived from the studies of Enright PL \& Sherrill DL [3] for healthy adults.

\section{Optimal reference equations}

From healthy population based samples using 6MWD methods are not yet available, several authors [1-16], determined factors affecting 6MWD in healthy adults and proposes the reference equation or normative data for 6MWT outcome (Table 1). When 6MWD is reduced a thorough search for the cause of the impairment should be made i.e. PFT, Cardiac function, anklearm index, muscle-strength, nutritional status, orthopaedic and cognitive function.

\section{Interpreting the results}

Once 6MWD for a given patient is available we have calculated the predicted distance using equation from published studies of healthy people of same age group much like spirometry.

\section{Result}

\section{Patient'scharacteristics}

Table 1 shows the physiological characteristics of the patients and their relation with 6MWD. We evaluated 121 patients between 13-85 years of age, 32 smokers. 108 had respiratory disease, 12 had cardiac disease, most of the patients completed the test. Mean age, height and weight were $56.75+15.054$ years, $161.80+8.352 \mathrm{~cm}, 64.93+14.633 \mathrm{~kg}$ respectively. Mean FEV1\%, FVC\%, and FEV1/FVC\% were 63.49+18.837, 63.7+16.230, and $99.72 \%$ respectively. 
International Journal of Pulmonary \& Respiratory Sciences

Table 1: Demographic Characteristics of the Patients: mean values.

\begin{tabular}{|c|c|c|c|c|}
\hline Variables & All $(\mathrm{n}=121)$ & Male $(\mathrm{n}=75)$ & Female $(\mathrm{n}=46)$ & $\mathrm{P}$ \\
\hline Age(years) & $56.75 \pm 15.054$ & $58.36 \pm 16.460$ & $54.13 \pm 121.143$ & $<0.005$ \\
\hline Height(cm.) & $161.80 \pm 8.352$ & $166.23 \pm 5.675$ & $154.59 \pm 6.872$ & $<0.001$ \\
\hline Weight (kg.) & $64.93 \pm 14.633$ & $64.44 \pm 13.850$ & $65.74 \pm 15.952$ & $<0.005$ \\
\hline B.M.I.(kg/m2) & $25 . \pm .042098$ & $24.0123 \pm 4.021$ & $26.0342 \pm 4.0341$ & N.S. \\
\hline 6MWD(m) & $390.08 \pm 143.211$ & $410.45 \pm 146.000$ & $356.13 \pm 133.164$ & 0.001 \\
\hline FEV1\% & $63.49 \pm 18.837$ & $61.31 \pm 18.919$ & $67.00 \pm 18.365$ & \\
\hline FVC\% & $63.71 \pm 16.230$ & $63.12 \pm 15.615$ & $64.65 \pm 17.307$ & \\
\hline FEV1/FVC\% & $99.7248 \pm 17.49029$ & $96.9069 \pm 18.88277$ & $104.2579 \pm 14.1720$ & \\
\hline
\end{tabular}

\section{As per pulmonary function test}

41(33.58\%) patients had obstructive airways disease of which 20 (18.2\%) had mild, 16 (13.2\%) moderate and 5 (4.1\%) had severe obstruction. 43 (35.53\%) had restrictive disease of which 27 (22.3\%) had mild, 13 (10.7\%) moderate, and 3 (2.5\%) had severe restriction.15 (12.40\%) had combined obstructive and restrictive disorder of which 3 (2.5\%) had mild, 7 (5.8\%) moderate and 5 (4.1\%) had severe disorder,22 (18.18\%) had normal spirometry. Mean 6MWD was 390.08+143.211m (range 264.769-533.29). 51 patients walked $>400 \mathrm{~m}, 24$ between 300 $400 \mathrm{~m}, 19$ between $200-300 \mathrm{~m}, 11$ between $100-200 \mathrm{~m}$, and 2 patients walked $<100 \mathrm{~m}$.

a) In males: Total patients were 75 , mean age, height and weight were $58.36+16.460$ years, $166.23+5.675 \mathrm{~cm}$, $64.44 \mathrm{~kg}+13.850$ respectively. Mean FEV1\%, FVC\% and FEV1/ FVC\% were $61.31+18.919,63.12+15.615,96.90 \%+18.88277$. 6MWD was 410.45+146.000m (264.45-556.45).

b) In females: Total patients were 46, mean age, height and weight were, $54.13+12.143 \mathrm{yrs}, 154.59+6.872 \mathrm{~cm}$, $65.74+15.952 \mathrm{~kg}$. Mean FEV1\%, FVC\% and FEV1/FVC\% were $67.00+18.365,64.65+17.30,104.2579+14.01720$ respectively. 6MWD was 356.13+133.164m (222.966-489.294) 6MWD was lower in females. Disease wise 6MWD (Table 2 \& Figure 1) was $290.8+121.997 \mathrm{~m}(89-411)$ in COPD, 207+112.834m (100-430) in IPAH, 330.72+120.906 m (151-525) in ILD, 385.45+141.408 $m$ (198-55)in CHF,473.00+106.828m (250-655) in BA, 418+114.698 m (146-655) in Bronchiectesis. 101 (83.40\%) patients completed 6MWT of which $31(30 \%)$ had to stop during walking for few seconds but resumed walking, 20 (16.50\%) patients could not complete the test, and the test had to be terminated the various reasons were breathlessness, giddiness, fatigue, tiredness, chest heaviness, drop in saturation.

Table 2: Disease wise distribution of patients and 6MWD.

\begin{tabular}{|c|c|c|c|}
\hline Diagnosis & Mean & N & Std. Deviation \\
\hline B.A. & 473.00 & 36 & 106.828 \\
\hline BRE & 418.33 & 9 & 114.695 \\
\hline C.H.D. & 385.42 & 12 & 141.408 \\
\hline C.K.D. & 410.00 & 2 & 56.569 \\
\hline
\end{tabular}

\begin{tabular}{|c|c|c|c|}
\hline C.O.P.D. & 290.81 & 21 & 121.997 \\
\hline EOSINOPHILIA & 540.00 & 1 & $\cdot$ \\
\hline HEALTHY & 540.00 & 1 & $\cdot$ \\
\hline I.L.D. & 330.72 & 18 & 120.906 \\
\hline METASTESIS Ca & 312.00 & 1 & $\cdot$ \\
\hline OHS & 533.00 & 1 & $\cdot$ \\
\hline OLD TBP & 288.00 & 2 & 144.250 \\
\hline P.H.T. & 207.14 & 7 & 112.834 \\
\hline Pneumonectomy & 432.00 & 1 & $\cdot$ \\
\hline R.A.D.S. & 600.00 & 1 & $\cdot$ \\
\hline S.L.E. & 300.00 & 1 & $\cdot$ \\
\hline SARCOIDOSIS & 543.00 & 5 & 87.293 \\
\hline SCLERODERMA & 514.00 & 1 & $\cdot$ \\
\hline Total & 390.08 & 120 & 143.211 \\
\hline
\end{tabular}

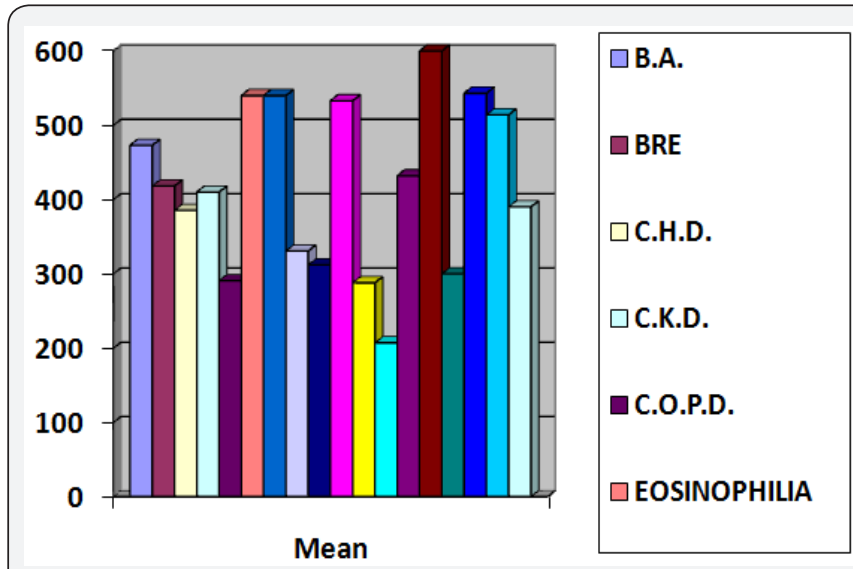

Figure 1: Disease wise distribution of patients and 6MWD.

As per reference [6] 55 (46\%) patients achieved lower limit of normal (LLN), 15 (12.50\%) achieved target walk distance. Disease wise COPD 4(19\%), ILD 8 (44.44\%), PHT 2 (28.37\%), CHD 8 (90\%), Sarcoidosis 4 (80\%), Bronchiectasis 4 (44.44\%) and B.A. $22(60 \%)$ patients achieved LLN.1 patient achieved target walk distance in COPD, ILD 3 (16.66\%), Sarcoidosis 2 (40\%), PHT 1(14.30\%), Bronchial Asthma 9 (24.32\%) and others $1(14.30 \%)$ could achieved target walk distance. 


\section{International Journal of Pulmonary \& Respiratory Sciences}

\section{Correlation between 6MWD and various physiological and pulmonary parameters}

Table 3: Correlations between 6MWD and various physiological and pulmonary parameters.

\begin{tabular}{|c|c|c|}
\hline & & Six Min Walk \\
\hline \multirow{3}{*}{ AGE } & Pearson Correlation - $r$ & $-.387(* *)$ \\
\hline & Sig. (2-tailed) p & .000 \\
\hline & $\mathrm{N}$ & 120 \\
\hline \multirow{3}{*}{ SEX } & Pearson Correlation - $r$ & $-.184(*)$ \\
\hline & Sig. (2-tailed) p & .044 \\
\hline & $\mathrm{N}$ & 120 \\
\hline \multirow{3}{*}{ HEIGHT } & Pearson Correlation - $r$ & $.285\left(^{* *}\right)$ \\
\hline & Sig. (2-tailed) p & .002 \\
\hline & $\mathrm{N}$ & 120 \\
\hline \multirow{3}{*}{ WEIGHT } & Pearson Correlation - $r$ & $.219\left(^{*}\right)$ \\
\hline & Sig. (2-tailed) p & .016 \\
\hline & $\mathrm{N}$ & 120 \\
\hline \multirow{3}{*}{ B.M.I. } & Pearson Correlation - $r$ & .061 \\
\hline & Sig. (2-tailed) p & .505 \\
\hline & $\mathrm{N}$ & 120 \\
\hline \multirow{3}{*}{ borgescale } & Pearson Correlation - $r$ & $\left.-.659{ }^{* *}\right)$ \\
\hline & Sig. (2-tailed) p & .000 \\
\hline & $\mathrm{N}$ & 117 \\
\hline \multirow{3}{*}{ mmrc_pre } & Pearson Correlation - $r$ & $-.455\left(^{* *}\right)$ \\
\hline & Sig. (2-tailed) p & .000 \\
\hline & $\mathrm{N}$ & 94 \\
\hline \multirow{3}{*}{ SMOKER } & Pearson Correlation - $r$ & $-.211\left(^{*}\right)$ \\
\hline & Sig. (2-tailed) p & .030 \\
\hline & $\mathrm{N}$ & 107 \\
\hline \multirow{3}{*}{ FEV1 } & Pearson Correlation - $r$ & $.404(* *)$ \\
\hline & Sig. (2-tailed) p & .000 \\
\hline & $\mathrm{N}$ & 119 \\
\hline \multirow{3}{*}{ FVC } & Pearson Correlation - $r$ & $.484(* *)$ \\
\hline & Sig. (2-tailed) p & .000 \\
\hline & $\mathrm{N}$ & 119 \\
\hline
\end{tabular}

\begin{tabular}{|c|c|c|}
\hline \multirow{3}{*}{ RatFEV1FVC } & Pearson Correlation - $r$ & -.030 \\
\hline & Sig. (2-tailed) p & .748 \\
\hline & $\mathrm{N}$ & 119 \\
\hline \multirow{3}{*}{ mmrcpost } & Pearson Correlation - $r$ & $-.613(* *)$ \\
\hline & Sig. (2-tailed) p & .000 \\
\hline & $\mathrm{N}$ & 108 \\
\hline \multirow{3}{*}{ borgescalepost } & Pearson Correlation - $r$ & $-.687\left({ }^{* *}\right)$ \\
\hline & Sig. (2-tailed) p & .000 \\
\hline & $\mathrm{N}$ & 117 \\
\hline \multirow{3}{*}{ spo2_pre } & Pearson Correlation - $r$ & $.382(* *)$ \\
\hline & Sig. (2-tailed) p & .000 \\
\hline & $\mathrm{N}$ & 120 \\
\hline \multirow{3}{*}{ Spo2_post } & Pearson Correlation - $r$ & $.439(* *)$ \\
\hline & Sig. (2-tailed) p & .000 \\
\hline & $\mathrm{N}$ & 120 \\
\hline \multirow{3}{*}{ rr_pre } & Pearson Correlation - $r$ & $-.455\left(^{* *}\right)$ \\
\hline & Sig. (2-tailed) p & .000 \\
\hline & $\mathrm{N}$ & 120 \\
\hline \multirow{3}{*}{ rrpost } & Pearson Correlation - $r$ & $-.418\left(^{* *}\right)$ \\
\hline & Sig. (2-tailed) p & .000 \\
\hline & $\mathrm{N}$ & 120 \\
\hline
\end{tabular}

(Tabb 3) Male tend to be significantly taller and BMI less than female. Significant positive correlation found between 6MWD and height $(\mathrm{p}<0.002, \mathrm{r}-=0.285)$ and weight $(\mathrm{p}<0.016, \mathrm{r}=$ 0.219 ), but no correlation was found between 6MWD and B.M.I. Significant negative correlation found between age $(p=0.000, r$ $=0.387)$, Borg score of dyspnoea, fatigue $(\mathrm{p}=0.000, \mathrm{r}=0.659)$, and MMRC score of dyspnea $(p=0.000, r=0.455)$, (correlation was more significant post-test for Borg and MMRC Score $(\mathrm{p}=0.000$, $\mathrm{r}=0.687$ and $\mathrm{p}=0.000, \mathrm{r}=0.613)$ and smoking $(\mathrm{p}<0.030, \mathrm{r}=0.211)$. Significant positive correlation found between spirometry values FEV1\% and FVC\% ( $\mathrm{p}=0.000, \mathrm{r}=0.404, \mathrm{P}=0.000, \mathrm{r}=0.484$ respectively) and SPO2 pre and post-test $(\mathrm{p}=0.000, \mathrm{r} 0.382$, $\mathrm{p}=0.000, \mathrm{r}=0.439$ respectively.

\section{Discussion}

Table 4: Mean 6MWD (in meters) by various authors for all subjects (men and women) and comparison with our study.

\begin{tabular}{|c|c|c|c|c|}
\hline Study & All Subjects & Men & Women & Significant Difference \\
\hline Enright \& Sherril et al [3] & & $576(391-728)$ & $494(310-664)$ & yes \\
\hline Gibbons WJ, et al [9] & $698 \pm 96$ & $687 \pm 89$ & $583 \pm 53$ & yes \\
\hline Chetta & & $638 \pm 44$ & $593 \pm 57$ & yes \\
\hline $\begin{array}{c}\text { CamarniB \& Eastwood P } \\
{[12]}\end{array}$ & $659 \pm 62$ & $685 \pm 49$ & $628 \pm 59$ & no \\
\hline $\begin{array}{c}\text { Hermion, Poh, PeterR. } \\
\text { Eastwood et al Singapore }\end{array}$ & $560 \pm 105$ & $586 \pm 126$ & $538 \pm 82$ & yes \\
\hline Li et al & & $680 \pm 65$ & $642 \pm 58$ & yes \\
\hline Almeri et al & & $429 \pm 47$ & $386 \pm 45$ & \\
\hline
\end{tabular}




\section{International Journal of Pulmonary \& Respiratory Sciences}

\begin{tabular}{|c|c|c|c|c|}
\hline Bennsad et al & & $711 \pm 81$ & $551 \pm 75$ & yes \\
\hline Icoama et al & & $622 \pm 80$ & $551 \pm 71$ & yes \\
\hline Troster et al [7] & $631 \pm 93$ & $524 \pm$ & $425 \pm$ & yes \\
\hline $\begin{array}{c}\text { Devshyam, et al [15] } \\
\text { (Indian) }\end{array}$ & $480 \pm 62.33$ & $482 \pm 89$ & $408 \pm 39.86$ & yes \\
\hline $\begin{array}{c}\text { Sivaranjani S, et al [16] } \\
\text { (Indian) }\end{array}$ & $445 \pm 55.64$ & $410.45 \pm 146$ & $356.13 \pm 164$ & yes \\
\hline Our study (Indian) & $390.08 \pm 143.211$ & & & \\
\hline
\end{tabular}

The ability to walk for a distance is an easy way to measure exercise capacity in patients with cardiac-pulmonary diseases. 6MWT is found to be an effective way of assessing exercise tolerance. We evaluated 121 adults, mean 6MWD was $390.80+143.211 \mathrm{~m}$, males cover more distance than females. We compared 6MWD with several studies done world over in healthy adults1-16 (Table 4). A reference equation published by Enright \& Sherril [3] found that age, gender height, and weight were independent factor associated with 6MWD. They administered 6MWT to 117 healthy man and 173 healthy women aged 40 to 80 years, the median distance walked was $576 \mathrm{~m}$ for man and $494 \mathrm{~m}$ for women. We selected this reference [3] equation for computation of 6MWD in our study: For Men: $6 \mathrm{MWD}=(7.57 \mathrm{x}$ height in $\mathrm{cm})-(5.02 \mathrm{x}$ age in yrs. $)-(1.76 \mathrm{xwt})-$.309 , alternative using B.M.I 1140m-(5.61X B.M.I.)-(6.94x age). For women: $6 \mathrm{MWD}=(2.11 \mathrm{x}$ height in $\mathrm{cm})-(2.29 \mathrm{x}$ wt. in $\mathrm{kg})-(1.76 \mathrm{x}$ age in yrs.)+667, alternative using B.M.I.: 1017m-(6.24x B.M.I.)(5.85x age in years) when using either equations we subtracted $153 \mathrm{~m}$ for men and $139 \mathrm{~m}$ for women as lower limit of normal (LLN). In our study mean 6MWD was $390+143.211$ m. The mean 6MWD values described in various studies1-16, was $613+93 \mathrm{~m}$ and $659+62 \mathrm{~m}$ in western and Caucasian healthy subjects respectively, compared to above studies our results were $62 \%$ (lower by $38 \%$ than western studies).There are two studies done in Indian healthy adults: Devshyam, et al [15] (281 healthy subjects mean 6MWD was $480+62.33 \mathrm{~m}$ ), and Sivaranjani SS, et al [16] (60 healthy subjects mean 6MWD was $445+55.64 \mathrm{~m}$ ) compared to these two studies our mean 6MWD were $82 \%$ and $87 \%$ lower by $18 \%$ and $13 \%$ respectively. Al Ameri [17] studied 129 Saudi Arab subjects, mean 6MWD was 341+70 $\mathrm{m}$, compared to our study it was significantly lower, marked difference in above study may be due to selection of the patients,
(COPD (37\%), PHT (1\%), ILD (62\%)). In our study we selected all types of patients, when calculated for COPD, ILD, PHT, 6MWD was $283 \mathrm{~m}$ which is lower by $18 \%$. In our study mean $6 \mathrm{MWD}$ value in male and female patients were $410.45+146.000$ and $356.13+133.164 \mathrm{~m}$ respectively. Compared to study done by Paul Enright \& D Sherril [3] (6MWD in healthy adult males and females, mean 6MWD were $576 \mathrm{~m}$ and $494 \mathrm{~m}$ respectively), our mean 6MWD values were $71.17 \%$ (29\% lower) in males and $72 \%$ (28\% lower) in females respectively. In comparisons to study done by: (1) Devshyam, et al. [15] (mean 6MWD were 524 and $425 \mathrm{~m}$ in males and females), our study showed significant lower value of 6MWD [410m (78.84\%) and 356m (76\%), lower by $22 \%$ and $24 \%$ ]. (2) S. Sivaranjani S, et al [16] (6MWD were $482+45.89$ and $408+29.86 \mathrm{~m}$ in males and females respectively), our study showed lower values of 6MWD [410 m (85.41\%) and $356 \mathrm{~m}(87.24 \%)$ lower by $15 \%$ and $13 \%$ respectively]. In our studied population the 6MWD has a significant correlation with various physiological and pulmonary parameters (Table 4). Positive correlation found with height ( $\mathrm{p}<0.002, \mathrm{r}=0.285$,) and weight $(p<0.016, r=0.219)$. Significant negative correlation found with gender $(\mathrm{p}<0.044, \mathrm{r}=0.184$ males covered more distance than females, normal reference values are lower in females than males) and age $(p=0.000, r=0.659)$. 6MWD was positively correlated with FEV1 $(p=0.000, r=0.404), \quad F V C \%$ $(\mathrm{p}=0.000, \mathrm{r}=0.484)$ and oxygen saturation pre and post $(\mathrm{p}=0.000$, $r=0.382, p=0.000, r=0.439$ respectively). 6 MWD decreases with decrease in FEV1, FVC and SPO2, and inversely correlated with Borg score of dyspnea ( $p=0.000, r=0.659)$ and MMRC Scale $(p=0.000, r=0.455)$ of dyspnea, as the age, Borg and MMRC scale of dyspnea increases 6MWD decreases, also smoking $(\mathrm{p}<0.300$, $\mathrm{r}=0.211$ ) decreases the $6 \mathrm{MWD}$.

\section{Disease Specific Discussion (Table 5)}

Table 5: Correlation between 6 MWD severity and disease severity.

\begin{tabular}{|c|c|c|c|c|c|c|}
\hline \multirow{2}{*}{ Total } & & \multicolumn{3}{|c|}{ 6min Walk Distance } & Total \\
\cline { 2 - 7 } & & $\begin{array}{c}\mathbf{1 . 0 0} \text { Normal } \\
(>=350)\end{array}$ & $\begin{array}{c}\mathbf{2 . 0 0} \text { Mild } \\
(\mathbf{2 5 0 - 3 4 9 )}\end{array}$ & $\begin{array}{c}\mathbf{3 . 0 0} \text { moderate } \\
(\mathbf{1 5 0 - 2 4 9 )}\end{array}$ & $\begin{array}{c}\mathbf{4 . 0 0} \text { Severe } \\
(<=\mathbf{1 4 9 )}\end{array}$ & $\begin{array}{c}\mathbf{1 . 0 0} \text { Normal } \\
(>=350)\end{array}$ \\
\hline B.A. & Count & 32 & 4 & 0 & 0 & 36 \\
\hline BRE & \% within diagnosis & $88.90 \%$ & $11.10 \%$ & $0.00 \%$ & $0.00 \%$ & $100.00 \%$ \\
\hline & \% within diagnosis & $77.80 \%$ & $11.10 \%$ & $0.00 \%$ & $11.10 \%$ & $100.00 \%$ \\
\hline C.H.D. & Count & 7 & 2 & 3 & 0 & 12 \\
\hline
\end{tabular}




\section{International Journal of Pulmonary \& Respiratory Sciences}

\begin{tabular}{|c|c|c|c|c|c|c|}
\hline & $\%$ within diagnosis & $58.30 \%$ & $16.70 \%$ & $25.00 \%$ & $0.00 \%$ & $100.00 \%$ \\
\hline \multirow[t]{2}{*}{ C.K.D. } & Count & 2 & 0 & 0 & 0 & 2 \\
\hline & $\%$ within diagnosis & $100.00 \%$ & $0.00 \%$ & $0.00 \%$ & $0.00 \%$ & $100.00 \%$ \\
\hline \multirow[t]{2}{*}{ C.O.P.D. } & Count & 7 & 6 & 4 & 4 & 21 \\
\hline & $\%$ within diagnosis & $33.30 \%$ & $28.60 \%$ & $19.00 \%$ & $19.00 \%$ & $100.00 \%$ \\
\hline \multirow[t]{2}{*}{ EOSINOPHILIA } & Count & 1 & 0 & 0 & 0 & 1 \\
\hline & $\%$ within diagnosis & $100.00 \%$ & $0.00 \%$ & $0.00 \%$ & $0.00 \%$ & $100.00 \%$ \\
\hline \multirow[t]{2}{*}{ HEALTHY } & Count & 1 & 0 & 0 & 0 & 1 \\
\hline & $\%$ within diagnosis & $100.00 \%$ & $0.00 \%$ & $0.00 \%$ & $0.00 \%$ & $100.00 \%$ \\
\hline \multirow[t]{2}{*}{ I.L.D. } & Count & 8 & 4 & 6 & 0 & 18 \\
\hline & $\%$ within diagnosis & $44.40 \%$ & $22.20 \%$ & $33.30 \%$ & $0.00 \%$ & $100.00 \%$ \\
\hline \multirow[t]{2}{*}{ METASTETIC Ca } & Count & 0 & 1 & 0 & 0 & 1 \\
\hline & $\%$ within diagnosis & $0.00 \%$ & $100.00 \%$ & $0.00 \%$ & $0.00 \%$ & $100.00 \%$ \\
\hline \multirow[t]{2}{*}{ OHS } & Count & 1 & 0 & 0 & 0 & 1 \\
\hline & $\%$ within diagnosis & $100.00 \%$ & $0.00 \%$ & $0.00 \%$ & $0.00 \%$ & $100.00 \%$ \\
\hline \multirow[t]{2}{*}{ OLD TBP } & Count & 1 & 0 & 1 & 0 & 2 \\
\hline & $\%$ within diagnosis & $50.00 \%$ & $0.00 \%$ & $50.00 \%$ & $0.00 \%$ & $100.00 \%$ \\
\hline \multirow[t]{2}{*}{ P.H.T. } & Count & 1 & 0 & 4 & 2 & 7 \\
\hline & $\%$ within diagnosis & $14.30 \%$ & $0.00 \%$ & $57.10 \%$ & $28.60 \%$ & $100.00 \%$ \\
\hline PNEUMONECTOMY & Count & 1 & 0 & 0 & 0 & 1 \\
\hline
\end{tabular}

COPD: The FEV1 is often used to grade the severity of disease; however patients with COPD have systemic manifestations that are not reflected by the FEV1\%. Several factors have been identified that predict poor survival in COPD these includes low FEV1, active smoking, hypoxemia, poor nutrition, presence of corpulmonale, resting tachycardia, lower exercise capacity, severe dyspnea, poor health related quality of life, anemia, frequent exacerbations, co-morbid illness, and low DLCO. Patients with FEV1 $<35 \%$ predicted have about $10 \%$ mortality per year, if patient reports that they are unable to walk 100 meters without stopping because of breathlessness, the 5-year survival is only $30 \%$. A multidimensional prognostic index [17] that takes into account several indicators of COPD prognosis are the BODE Index. Inclusion of 6MWD along with FEV1, dyspnea rating and BMI into a 10-point index was better at predicting mortality in COPD than FEV1 alone. B.R. Celli, Cote C.G., JM Martin et al. [18] evaluated 207 patients and found that above four factors predicted the risk of death in this cohort: in which a higher score indicates a higher risk of death. The hazard ratio (HR) for death from any cause increased by 1.34 per point increase in BODE INDEX (95\% confidence interval 1.26 to 1.42 , $\mathrm{p}<0.001)$ and HR for respiratory cause was 1.62 (95\% confidence interval-1.48 to $1.77, \mathrm{p}<0.001$ ). "0" point is given for $6 \mathrm{MWD}>350 \mathrm{~m}, 1$ point for 250-349 m, 2 points for 150-249 m, and 3 points for $<149 \mathrm{~m}$. This demonstrate the independent role that exercise capacity measured by 6MWT has in predicting mortality in COPD. In our study we had 21 patients of COPD 18 male (all were smokers), 3 female (non-smokers), mean 6MWD was 290.81meters (range 89 to 401 meters), 9 patients could not complete 6MWT due to dyspnea, fall in saturation, only one patient could achieved
Target 6MWD (100\%), as per ref 6 equation 3 patients could not achieve lower limit of normal distance walk, 4 patients walked $<149$ meters only ( 3 points), 4 patients walked between 150 249 meters ( 2 points), 6 patients walked between 250-349 meters ( 1 point) and 7 patients walked $>350$ meters ( 0 point). As per BODE INDEX: 2 patients had score of " 10 ", 2 patients had score of "9", 1 patient had score of "8", 5 patients had score of "7", 2 patients had score of " 5 ", 9 patients had score of " $2-4$ ". A BODE score $>7$ is associated with 30\% 2 years' mortality, where as a score of 5-6 is associated with 15\% 2 years' mortality, if BODE score is $<5$ the 2 years' mortality is less than $10 \%$. In our study 10 patients had BODE score of $>7,2$ patients had score of 5 , and 9 patients had score $<5$ that can predict 2 yrs. mortality, which is higher in 12 patients in our study. In another study done by Szekely LA, et al [19] they evaluated 47 subjects preoperatively for LVRS a 6MWD $<200$ meters had a specificity of $84 \%$ for prediction of 6 months mortality after LVRS for emphysema. Patients with unacceptable risk for this procedure were identified by the $6 \mathrm{MWT}$ and a resting PCO2>45 mmHg. In our study 6 patients walked $<200$ meters which is significant. In a study done by Casanova C, Cote C, JM Martin, et al. [20] for 576 COPD patients with wide range of airflow obstruction seen at 4 centers in two countries reported on the value of 6MWD and Spo2 during 6MWT, 6MWD was a good independent predictor of all cause and respiratory mortality particularly for the group with FEV $1<50 \%$ of predicted and fall in Spo $2>4 \%$ or to $<90 \%$. In our study 11 patients had FEV1 $<50 \%$ with 10 patient's $6 \mathrm{MWD}<350 \mathrm{~m}$ with fall in saturation $>4 \%$ during exercise test (Spo2<90\%). In a mixed group of patients with advanced lung disease undergoing evaluation for lung transplantation a study 
done by Kadikar A, [21] many of had severe COPD, 6MWD was $<300$ meters had a $80 \%$ mortality rate. In our study we have 9 patients who had severe COPD 5 walked $<300$ m another 5 patients who had combined obstructive and restrictive disorder walked $<300$ meters, in all these patients 6MWD predicts higher mortality.

Idiopathic Pulmonary Arterial Hypertension: In patients with Idiopathic pulmonary hypertension 6MWD was significantly but modestly related with New York Heart association functional class, baseline cardiac output, pulmonary vascular resistance, but not mean pulmonary artery pressure. A study done by Shoichi Miyamoto, John Satohet, et al [22] in 43 patients with pulmonary hypertension together with echocardiography, right heart catheterization and measurement of plasma epinephrine and norepinephrine. Symptom related cardiopulmonary exercise performed in a sub sample of patients $(n=27)$ distance walked in 6 minutes was significantly shorter in patients than in age and sex matched subjects $(297+188$ versus $655+91 \mathrm{~m}$, $\mathrm{p}<0.001$ ). The distance walked had strong significant correlation with CPET parameters. Among the various parameters only 6MWD <332 meters independently related to mortality by multivariate analysis. Patients had a lower survival than those walking further. In our study we had 7 patients of pulmonary hypertension out of which 5 patients walked $<250$ meters and 2 walked $<140$ meters, indicating higher mortality. In another study done by Paciocco G, et al [23] 6 MWD $<300$ meters and reduction of saturation $>10 \%$ at the end of $6 \mathrm{MWT}$ was associated with increased mortality with an HR of 2.4 and 2.9 respectively. In our study 7 patients of pulmonary hypertension 5 patients walked $<300 \mathrm{~m}$ with 2 patients desaturases $>10 \%$ at the end of the test which is quite significant.

Idiopathic Pulmonary Fibrosis: The importance of measuring oxygen desaturation during 6MWT was highlighted in a study of patients with IPF by Flaherty KB, et al [24] which showed that a decrease in SPO2 during exercise had prognostic value though ATS does not recommends measurement of SPO2 during test, 6MWD was a weak predictor of mortality which was no longer significant when patients were split into presence or absence of $\mathrm{SPO} 2<88 \%$ during exercise. Patients with an $\mathrm{SPO} 2<$ $88 \%$ during their $6 \mathrm{MWT}$ had a median survival time of 3.2 years, compared to 6.8 years in those with lesser degree of oxygen desaturation. Even in those with a milder degree of desaturation, a 10-point increase in desaturation area gave HR for mortality of 1.33 ( $95 \%$ confident interval, 1.08 to $1.63 \mathrm{p}=0.007$ ). For patients with baseline 6 MWT SPO2 $<88 \%$ the best predictor of mortality was serial decrease in diffusion capacity of carbon mono-oxide [25]. In those with lesser degrees of 6MWT desaturation at baseline serial decrease in FVC and increase in desaturation significantly predicted mortality. In our study 12 patients' desaturases $>4 \%$ (range 4 to $9 \%$ ) (base line spo $2<88 \%$ ). This finding highlights the importance of measurement of spo2 during 6MWT to assess prognosis, an approach specifically not recommended by ATS. In our study 3 patients could not complete the 6MWT due to severe dyspnea, tachypnea, and drop in saturation $>4 \%$, 15 patients completed 6MWT, 8 stopped due to dyspnea and drop in SPO2 $>4 \%$ for $15-30$ seconds but continue walking after rest. In another study by Vibha N Lama et al [26] prognostic value of desaturation during 6MWT in IPF patients, exercise induced hypoxia is an index of the severity of ILD. Desaturation during 6MWT predict mortality for patients with UIP ( $n=83)$ and NSIP ( $n=27)$, desaturation is defined fall in saturation $<88 \%$ or less during $6 \mathrm{MWT}$. Patients desaturated had higher mortality than those who did not have.

Chronic heart failure: 12 patients ( 9 males, 3 female) mean $6 \mathrm{MWD}$ is $385.42+408 \mathrm{~m}, 2$ patients could not complete the test due to drop in saturation $>4 \%, 5$ patients could not achieve lower limit of normal walk distance. 2 patients achieved Target walk distance. In patients with CHF strong correlation between 6MWD and exercise ergometry and V02 max were observed by several researchers and moderate to strong association with NYHA functional classification. Results of other studies in the same population have shown that distance walked in 6MWT $(<300 \mathrm{~m})$ can identify those with increased likelihood of death or hospitalization within a time frame ranging from 3 months to 1 year. In our study 5 patients walked $<300 \mathrm{~m}$ out of which only one could achieve lower limit of normal 6 minute walk distance. In a study done by Lipkin DP, et al [27] 26 patients with mean age of 58 years (range 36-58) with stable CHF NYHA class II \& III and 10 normal subjects of similar age there was significant difference in walking distance between normal, CHF patients with class II \& III $(683,558$, and $402 \mathrm{~m})$ respectively, the distance walked varies with oxygen consumption. In a study done by Shah $\mathrm{MR}$, et al [28] in patients with congestive heart failure (CHF) those with a 6MWD below a median of $218 \mathrm{~m}$ had a 4-6-fold higher mortality risk for every $100 \mathrm{~m}$ decrease in 6MWD, the HR for death, hospitalization and the composition of the two end points was $0.58,0.85$ and 0.75 respectively. In another CHF study done by Passantino A, et al [29] 6MWD and short term change in 6MWD in response to change to therapy were significant independent predictor of survival. Prognostic value of 6MWT in stable CHF patients a study by Sakir Arslam et al [30] with two groups of patients, death risk was higher in patients with a distance of $<300 \mathrm{~m}(\mathrm{p}=0.05)$ with $\operatorname{LVEF}<0.30(\mathrm{p}=0.02)$. Studies of Left Ventricular Dysfunction (SOLVED) was the first large investigation (898 patients) by Bittener, et al [31] to show a strong correlation between distance walked during 6MWT and death (decrease in distance walked increases the mortality). In our study 5 patients walked $<300 \mathrm{~m}$. with drop in saturation showed increased mortality.

Bronchiectasis: Total 9 patients (5male, 4 female) 2 patients could not complete the test due to drop in saturation, tachypnea, and dyspnea, 4 patients could not achieve lower limit of normal distance, 8 patients could not achieve Target walk distance, 4 patients had $>4 \%$ drop in saturation. In a study by Lee $\mathrm{A}^{31}$ 6MWD severity of disease and HRQOL had a stronger association compared to physiological measures of disease severity. 
Sarcoidosis: 5 patients with mean 6MWD-543.0 +87.293m all patients walked $>400 \mathrm{~m}$ and achieved lower limit of normal walk distance, only one patient achieved Target walk distance, all had $>4 \%$ drop in saturation during 6MWT but all completed 6MWT, 3 patients became tachyponic with respiratory rate $>24$ / mt. In a study done by Bittener, et al [31] for 26 Saudi patients with pulmonary sarcoidosis all completed 6MWT female covered shorter distance than males, lowered Spo2 at end of test than others, mean 6MWD for entire cohort was $364 \mathrm{~m}$, females < than males [343m (223-389) vs 416m (352-500m), with significant lower Spo2 at end of 6MWT than male [90.5\% (61-99\%) vs $96 \%$ (75-98\%). In our study there was no such difference seen in distance walked in 6 minutes but all patients had drop in saturation $>4 \%$ which is significant [33-36].

Bronchial Asthma: 37 patients (18 male, 19 female), 1had severe, 7 moderate, 14 mild, 15 patients had normal disease, all had completed 6MWT, 8 male and 4 female became tachyponic with 8 had $>4 \%$ drop in saturation, 33 patients walked $>350 \mathrm{~m}, 4$ walked between $150-249 \mathrm{~m}, 10$ patients could not achieved lower limit of normal (LLN) as per reference equation, all had long standing Bronchial Asthma.In a study done by AL Ameri35 for respiratory disease patients $6 \mathrm{MWD}$ was significantly correlated with FEV1 patients.

Other patients: (1Carcinoma lung, 2RADS, 1Tuberculosis, 2CKD, 1Pneumonectomy all patients completed the test except 1T.B. patient), 5 walked $>350 \mathrm{~m}, 1$ between $250-349 \mathrm{~m}, 1<249 \mathrm{~m}$ (150-249).

\section{Conclusion}

In our study we demonstrated that 6MWT can be safely performed. Its validity reliability, and reproducibility were studied in several populations world over [1-16]. As per our knowledge this is one of the study done in Indian population, with no untoward events or complications that required emergency management, was highly tolerable in different age groups, gender and in patients with advanced cardiacrespiratory conditions, only few patients could not complete the test. 6MWD is a useful marker for the severity and progression of the disease. The co-relation of 6MWT and PFT, in patients with respiratory diseases makes this test easy and simple tool for assessing the disease status. 6MWD was lower in females and had significant positive correlation with height, FEV1, FVC, SPO2, and negative correlation with age, Borg and MMRC scale of dysponea and smoking.

\section{Contributors}

All the authors designed the study, review the case, revised and checked it. PKV wrote the manuscript, prepared tables and images, reference collection, and obtained informed consent from the patient. PSB and GBG helped smooth conduction of the test, helped in writing manuscript. SVR consultant Respiratory Physician reviewed draft, supervised whole procedure suggested improvements. JRS, HOD helped in conducting, selection of place, reviewed draft, RSM helped in preparation of draft, suggested reviews and references.

\section{Acknowledgement}

Our sincere thanks to Dr. A.S. Chitnis Senior pulmonologist and D.N.B. Teacher for his technical guidelines and help provided. We are also thankful to the staff of pulmonary and physiotherapy department, to the management of Jaslok Hospiatl to allow us to conduct this study and to all the participants.

\section{References}

1. American Thoracic Society (ATS) Statement guidelines, for the sixminute walk test. AM.J. Respir. Crit.Med.2002; 166:111-117.

2. Pulmonary Rehabilitation Toolkit (2006) assessing exercise and standardization of 6 MWT http/www.pulmonaryrehab.com.au.

3. Enright PL, Sherill DL Reference equations for the six-minute walk test in healthy adults, Am.J. Respir Crit Care Med 1998; 158: 1384-1387.

4. Alison, Anderson (1981) Six-minute walk test and exercise prescription. Phys Ther 61: 1278-1280.

5. Leach (1992) Improvement in the performance of test with training effects and oxygen supplementation. Thorax 47: 781-789.

6. Probst (2005) Standardized encouragement, medications and use of a wheeled walking frame. Chest 126: 1102-1107.

7. Trooster T, Gooselink R, Decramer M (199) Six-minute walking distance in healthy elderly subjects. Eur Respir J 14(2): 270-274.

8. Brooks D, Solway S, Gibbons WJ (2003) ATS statement on Six-minute walk test. Am J Respir Crit Care Med 167(9): 1287.

9. Gibbons WJ, Brooks D, Solway S (2003) ATS statement on Six-minute walk test. Am J Respir Crit Care Med 167(9): 1287.

10. Bohannon Richard W (2007) Six minute walk test a meta-analysis of data from apparently healthy elders. Topics in Geriatric Rehabilitation 23(2): 155-160.

11. Roberta ER, Jessie JC (1999) Functional fitness normative scores for community residing older adults. Journal of Aging and Physical Activity 7(2): 162- 181.

12. Camarri B, Eastwood PR, Cecins NM, Thompson PJ, Jenkins S (200) Six minute walk distance in healthy subjects aged 55-75 years. Respir Med 100(4): 658-665.

13. Enright PL, McBurnie MA, Bittner V, Tracy RP, McNamara R, et al. (2003) The 6-min walk test: a quick measure of functional status in elderly adults. Chest 2003; 123(2): 387-398.

14. Casanova C, Celli BR, Barria P, Casas A, Cote C, et al. (2011) The 6-min walk distance in healthy subjects: reference standards from seven countries. Eur Respir J 37(1): 150-156.

15. Devasahayam, Christopher J, Naziya Tabassum (2007) 6MWD reference equation in healthy Indians, E-poster P-3526 European respiratory Annual congress 15-19.

16. Sivaranjini S1, Vanamail P, Eason J (2010) Six minute walk test in people with tuberculosis sequelae. Cardiopulm Phys Ther J 21(3): 5-10.

17. Hatem FS Al Ameri (2006) 6MWT in respiratory diseases: A university hospital experience. Annals of Thoracic Medicine 1(1): 16-19.

18. Celli BR, Cote CG, Marin JM, Casanova C, Montes de Oca M, et al (2004) The body mass index, airflow obstruction dyspnea, and exercise capacity index in chronic obstructive pulmonary disease. N Eng J Med 350(10): 1005-1012. 
19. Szekely LA, Oelberg DA, Wright C, Johnson DC, Wain J, et al (1997) Prepoerative predictors of morbidity and mortality in COPD patients undergoing bilateral lung volume reduction surgery. Chest 111(3): 550-558.

20. Casanova C, Cote C, Marin JM, Pinto-Plata V, de Torres JP, et al. (2008) Distance and oxygen desaturation during the Six-minute walk test as predictors of long term mortality in patients with C.O.P.D. Chest 134(4): 746-752.

21. Kadikar A, Maurer J, Ketson S (1997) Six-minute walk test: a guide to assessment for lung transplantation. J Heart Transplant 16(3): 313 319.

22. Miyamoto S, Nagaya N, Satoh T, Kyotani S, Sakamaki F, et al (2000) clinical correlates and prognostic significance of six-minute walk test in patients with primary pulmonary hypertension, comparison with cardiopulmonary exercise testing, Am J Respir Crit Care Med 161(2) 487-492.

23. Paciocco G, Martinez FJ, Bossone E, Pielsticker E, Gillespie B, et al (2001) Oxygen desaturation on the six-minute walk test and mortality in untreated pulmonary hypertension. Eur Respir J 17(4): 647-652.

24. Flaherty KR, Andrei AC, Murray S, Fraley C, Colby TV, et al. (2006) Idiopathic Pulmonary Fibrosis: prognostic value of changes in physiology and six-minute walk test. Am J Respir Crit Care Med 174(7): 803-809.

25. Mak VH, Bugler JR, Rberts CM, Spiro SG (1993) Effect of arterial oxygen desaturation on 6MWD, perceived effort and perceived breathlessness in patients with airflow limitation. Thorax 48: 33-38.

26. Lama VN, Flaherty KR, Toews GB, Colby TV, Travis WD, et al. (2003) Prognostic value of desaturation during 6mwt in IPF. Am J Respir Crit Care Med 168(9): 1084-1090.

27. Lipkin DP, Scriben AJ, Crake T, Poole-Wilson PA (1986) 6mwt for assessing exercise capacity in chronic heart failure. Br Med 292(6521): 653-655
28. Shah MR, Hasselblad V, Gheorghiade M, Adams KF, Swedberg K, et al (2001) Prognostic usefulness of the six-minute walk in patients with advanced congestive heart failure secondary to ischemic or nonischemic cardiomyopathy. Am J Cardiol 88(9): 987-993.

29. Passantino A, Lagioia R, Mastropasqua F, Domenico S (2006) Short term change in distance walked in six minutes is an indicator outcome in patients with chronic heart failure in clinical practice. J Am Coll Cardiol 48(1): 99-105.

30. Arslan S, Erol MK, Gundogdu F, Sevimli S, Aksakal E, et al. (2007) Prognostic value of 6MWT in stable outpatients with heart failure. Tex Heart Inst J 34(2): 166-169.

31. Bittner V, Weiner DH, Yusuf S, Rogers WJ, McIntyre KM, et al (1993) Prediction of mortality and morbidity with a six-minute walk test in patients with left ventricular failure dysfuction. SOLVD investigators. JAMA 270(14): 1702-1707.

32. Alhamad EH (2009) 6MWT in patients with pulmonary sarcoidosis. Ann Thorac Med 4(2): 60-64.

33. Rasekaba T, Lee AL, Naughton MT, Williams TJ, Holland AE (2009) The 6MWT a useful metric for cardiopulmonary patients. Intern Med J 39(8): 495-501.

34. Guyatt GH, Sullivan MJ, Thompson PJ, Fallen EL, Pugsley SO, et al (1985) The 6MW a new measure of exercise capacity in patients with chronic heart failure. Can Med Assoc J 132(8): 919-923.

35. Butland RJ, Pang J, Gross ER, Woodcock AA, Geddes DM (1982) Two, Six and 12-minute walk tests in respiratory disease. BMJ 284(6329): $1607-1608$.

36. Pinto-Plata VM, Cote C, Cabral H, Taylor J, Celli BR (2004) The 6MWD: change over time and value as a predictor of survival in severe COPD. Eur Respir J 23(1): 28-33.

\section{Your next submission with Juniper Publishers} will reach you the below assets

- Quality Editorial service

- Swift Peer Review

- Reprints availability

- E-prints Service

- Manuscript Podcast for convenient understanding

- Global attainment for your research

- Manuscript accessibility in different formats

( Pdf, E-pub, Full Text, Audio)

- Unceasing customer service

Track the below URL for one-step submission https://juniperpublishers.com/online-submission.php 